\title{
Construction and Standardization of Adolescence Education Programme (AEP) Attitude Scale
}

\author{
Bonnie Amonge Crerar \\ Ph.D. Research Scholar \\ Department of Education, Dibrugarh University \\ Prof. Neeta Kalita Barua \\ Department of Education, Dibrugarh University
}

\begin{abstract}
In the present paper, an attempt has been made to construct and standardize an Adolescence Education Programme attitude scale for the purpose of measuring the attitude of teachers towards AEP. The draft scale consisted of 94 items on the following four dimensions: (a) Adolescent Reproductive and Sexual Health (ARSH) (b) Reproductive tract infection and Sexual tract infection (RTI \& STI) (c) Substance Abuse and (d) Life Skills Education (LSE). Later, after item analysis and item selection the number of items was reduced to 77. The scale was standardized by computing the reliability and validity of the scale. Reliability was calculated by the split-half method and found to be .88 and hence satisfactory. To establish the validity of the scale, it was sent to subject experts, who affirmed the satisfactory coverage of the AEP contents, thus confirming its applicability in the real field.
\end{abstract}

\section{INTRODUCTION}

The AEP was introduced into the CBSE curriculum of classes IX to XII in the year 2007, with the sole motto of producing youngsters capable of making informed decisions, the prime focal areas being: Adolescent Reproductive and Sexual Health, Reproductive Tract Infection and Sexual Tract Infection (HIV and AIDS), Substance Abuse and Life Skills Education. This was done in consonance with the recommendations of the National Curriculum Framework (NCF) 2005, which states that education should instill 'independence of thought and action, sensitivity to others' wellbeing and feelings, learning to respond to new situations in a flexible and creative manner, predisposition towards participation in democratic processes, and the ability to work towards and contribute to economic processes and social change." Based on these principles, AE aims to provide young people with accurate, age appropriate and culturally relevant information; promote healthy attitudes and develop skills to enable them to respond to real-life situations effectively. Dissemination of the AEP was entrusted to the regular teachers, who were further trained and named as Master Trainers. These Master Trainers further trained other few teachers for the sake of assistance, named as Nodal Teachers. Teachers being pivotal, the effectiveness of the programme rested much in their hands. To what extent teachers would work to make the AEP programme a success would be much determined by their attitude towards the programme. The importance of one's attitude could well be estimated from the following definitions:

Thurstone (1946), "Attitude is the degree of positive and negative affects associated with some psychological object”.

Sorenson (1977), “An attitude is a particular feeling about something. It therefore involves a tendency to behave in a certain way in situations which involve that something, whether person, idea or object. It is partially rational and partially emotional and is acquired, not inherent in an individual".

Eagly (1992) "An attitude is an internal disposition that affects us in a variety of situations. More precisely, an attitude is an evaluative reaction towards someone or something that we reveal in our thoughts, feelings or intended actions toward that person or thing".

Eagly and Chaiken (1993), "Attitude is a psychological tendency that is expressed by evaluating a particular entity with some degree of favour or disfavor". 
Crano and Prislin (2006), “Attitudes are the evaluative judgements that integrate and summarize ... cognitive/affective reactions".

Besides the above there are some componential definitions of attitude (Katz and Stotland, 1959; Rosenberg and Hovland, 1960) known as CAB where C stands for Cognitive and includes ones beliefs, thoughts and attributes associated with an object; A stands for Affective and includes ones feelings and emotions linked to an object and $B$ stands for behaviour and refers to ones past behaviour and experiences regarding an object.

Thus, attitudes are evaluative in nature, affecting an individual's prevailing tendency to respond favourably or unfavourably to an object. As such the AEP teachers being no exception to the fact that their dissemination of AEP was much influenced by their attitude. Guided by the above theory the investigator decided to measure the CBSE school teachers' attitude towards the AEP by using an attitude scale. Although a Likert type AEP attitude scale was developed by National Population Education Project, NCERT; the investigator decided to develop a new Likert type AEP attitude scale. This was because the NCERT AEP attitude scale was found to be elusive of the Life Skills Education.

\section{ObJectives of the Present Study}

The main aim of the present study is to construct and standardize an AEP attitude scale. To realize this aim, the following objectives have been set:

2.1. To prepare the draft attitude scale.

2.2. To try out the draft attitude scale.

2.3. To carry out item analysis of the draft attitude scale.

2.4. To select items for the final attitude scale.

2.5. To determine the reliability of the attitude scale.

2.6. To determine the validity of the attitude scale.

\section{Operational Definition OF Key TERMS}

3.1. Construction: Here the term construction refers to the process followed in the development of the AEP attitude scale. Since decision was made to prepare a Likert type AEP attitude scale the researcher followed the steps as proposed by Rensis Likert.

3.2. Standardization: Standardization refers to the process of estimating the reliability and validity of the AEP Attitude scale so as to ensure the consistency, accuracy and truthfulness of the test scores and contents.

3.3. Adolescence Education Programme (AEP): Here AEP refers to the academic process of helping adolescent students in acquiring information and forming attitudes and beliefs on sex, sexual identity, relationships, Reproductive Tract Infection (RTI) and Sexual Tract Infection (STI), substance abuse, nutrition, gender sensitization and life skills, so as to help them make informed choices about their behaviour and feel confident and competent about acting on their choices.

3.4. Attitude Scale: In this study attitude, scale refers to the self-developed tool for collecting information on CBSE school teachers' mental predispositions towards AEP, being inferred through a set of written statements that are positive and negative evaluation of the object concerned, either conscious or unconscious.

\section{Preparation of the Draft Attitude Scale}

The steps followed were:

4.1 The researcher thoroughly studied the literature related to Adolescence education programme.

4.2 The researcher consulted other scales, such as:

a. Attitude scale towards sex education by Usha Mishra.

b. Questionnaire to study attitude of teachers towards sexuality and HIV and AIDS education by Tembela Nqoloba. 
c. Life skills- opinion questionnaire, Department of Psychiatry, National Institute of Mental Health and Neuro Science, Bangalore.

4.3 From the research literature the researcher included the following dimensions in the AEP attitude scale:

4.3.1. Adolescent Reproductive and Sexual Health: Teachers attitude towards dissemination of information regarding adolescent reproductive and sexual health and its impact on adolescent student behaviour. This dimension encompassed the following sub-dimensions:

4.3.1.0. Puberty and Adolescence: Information on the process of growing up and its associated changes.

4.3.1.1. Nutritional Needs during Adolescence: Constituents of balanced food and its importance for both sexes and best means for providing information.

4.3.1.2. Cognitive, Emotional, Moral and Social Development: Associated developmental characteristics and developmental tasks of adolescence period.

4.3.1.3. Reproductive and Sexual Health and Teenage Pregnancy: Reproductive organs and process of reproduction, means to safe sex, sexual rights, masturbation, homosexuality, initiation of information on sex.

4.3.1.4. Gender Sensitization: Effect of gender sensitization on women, marriage and society; female rights and gender equality. Best agency for dissemination of information. Cultural relevancy of gender sensitization.

4.3.2. Reproductive Tract Infection and Sexual Tract infection (HIV \& AIDS): Importance of sex education in preventing RTI \& STI, impact of RTI \& STI education on adolescent students, best agency for providing information on RTI \& STI.

4.3.3. Substance Abuse: Effect of knowledge regarding varied substances that can be abused and their consequences, on adolescent behaviour.

4.3.4. Life Skills Education (LSE): Need of LSE in school curriculum, impact of LSE on- adolescent behaviour, teacher student relationship, and society.

4.4 Keeping the above dimensions in mind the researcher prepared statements showing both favourable and unfavourable attitude. Against each item, five responses- Strongly Agree (SA), Agree (A), Undecided (U), Disagree (D) and Strongly Disagree (SD) had been provided. The subject was to tick any one from the given responses.

4.5 The statements were further modified on consultation with the Supervisor and Departmental experts. A total of 94 (ninety four) statements were selected of which 48 (fourty eight) were favourable and 46 (fourty six) were unfavourable.

4.6 All the statements were randomly arranged in a single format, to give form to the draft AEP attitude scale. The distribution of the selected items of the draft attitude scale is given in Table -1

4.7 The scoring key for each statement both favourable and unfavourable against five responses were determined as given in Table -2

4.8 Necessary instruction was prepared and placed at the beginning of the draft attitude scale.

4.9 To determine the time limit the draft attitude scale was administered upon 5 teachers (IX- XII) of Kendriya Vidyalaya School, Chabua, and it was found that they took 55 minutes in average to respond to the items. So 55 minutes was fixed as the time limit to respond to the draft attitude scale.

\section{Try OUt Of The Draft AEP ATtitude Scale}

5.1. For the purpose of try out a total of 150 teachers (Classes IX to XII) teaching in the CBSE affiliated schools of Jawahar Navodaya Vidyalaya and Kendriya Vidyalaya, were administered the draft AEP attitude scale. The sample selection was done using the purposive sampling technique. Table $\mathbf{- 3}$ shows the sample of the schools district wise along with number of teachers from each school. 
5.2. Administration of the draft attitude scale: The following procedure was adopted to administer the draft attitude scale

a) A good rapport was established with the responders by initiating some friendly talk.

b) Proper sitting arrangement was made and the draft attitude scale was distributed to the teachers. They were asked to read the given instruction carefully. Oral instruction was also given where necessary. After 55 minutes all the filled in draft attitude scale were collected.

\section{ITEM ANALYSIS}

Item analysis is a statistical procedure to identify the best items. The item analysis of the draft attitude scale was carried out by determining the ' $t$ ' value for each statement. The ' $t$ ' value is a measure of the extent to which a given statement differentiates between high group scorers and low group scorers. For determining the ' $t$ ' value the following steps were followed;

6.1 The responded draft attitude scale of all the 150 teachers were scored by using the afore mentioned scoring key i.e. 6.0.7. The scores for each individual respondent was then summed up and then arranged in descending order.

6.2 Then $25 \%$ (i.e. 38 teachers) from the high scoring group and $25 \%$ (i.e. 38 teachers) from the low scoring group were selected. The middle group scorers were discarded.

6.3 The mean score of each individual item for both high scoring group and low scoring group was computed.

6.4 Using the following formula the ' $t$ ' value for each item was found out:

$$
t=\frac{\bar{X}_{H}-\overline{X_{L}}}{\frac{\bar{\sum}\left(\mathbf{X}_{H} \ldots \mathbf{X}_{H}\right)^{2}+\bar{\sum}\left(\mathbf{X}_{L} \ldots \mathbf{X}_{L}\right)^{2}}{n(n-1)}}
$$

A ' $t$ ' value equal to and greater than 1.75 indicated that the average response of the high and low groups to a statement differed significantly (Edwards, 1957).

6.5 The items having ' $t$ ' value less than and greater than 1.75 were identified. Item number along with ' $\mathrm{t}$ ' value and remark is given in Table-4

Table-4 is evidential that out of 94 statements 80 statements have' $t$ ' value $\geq \mathbf{1 . 7 5}$. These items are shown dimension wise in Table-5

\section{ITEM SELECTION}

Out of 94 statement though 80 statements had ' $t$ ' value $\geq 1.75$ the investigator decided to select only 77 statements having ' $t$ ' value $\geq 1.88$ for the final draft attitude scale. Out of 77 statements 39 (thirty nine) were positive statements and 38 (thirty eight) were negative statements. The rejected items were Item No. 38, $57 \& 67$ (Table-4). The reason being that the value 1.75 had been suggested as a rule of thumb, which is an idiom meaning that the value had been out of experience found to be able to differentiate between the responses of the high scorers and low scorers provided the subjects in both the groups are 25 or more (Edwards), which is proof of the fact that the value is not a binding factor in selection of the items. As such the researcher decided to select items having ' $t$ ' value more closer to the value 2 (hence ' $t$ ' $\geq \mathbf{1 . 8 8}$ ) were selected

The selected statements were again rearranged and assigned new numerals to give form to the final draft of the AEP attitude scale. The following Table-6 gives the dimension wise distribution of the statements according to the numerals assigned to each one.

\section{Standardization of The AEP Attitude Scale}

8.1. Reliability: The reliability of the AEP Attitude scale was computed in the following manner:

8.1.1. As suggested by Likert and mentioned by Edwards the split half technique was followed for estimating the reliability of the scale. 
8.1.2. For the said purpose the scale was administered on a sample of 106 AEP teachers teaching in Jawahar Navodaya Vidyalaya (JNV) and Kendriya Vidyalaya (KV), situated in the various districts of Assam. The district wise and school wise distribution of the sample is presented in the following Table - 7:

8.1.3. After collection of the scripts the items were scored by using the scoring key as mentioned in Table 2. Then the items were split into two equal or nearly equal parts by following the odd-even method. The sum of the scores on the odd items and the even items of each individual subject was then estimated respectively.

8.1.4. Then by computing the Product Moment correlation (Pearson $\mathbf{r}$ ) from the raw scorers by using the following formula:

$$
r \frac{1}{2}=\frac{\sum X Y-N M_{X} M_{Y}}{\sqrt{\left[\Sigma X^{2}-N M_{X}^{2}\right]\left[\Sigma^{2}-N M_{Y}^{2}\right]}} \quad \text { Garret }
$$

the reliability of the half test was found to be $\mathbf{r}^{1 / 2}=.79$.

8.1.5. To the value of $\mathbf{r} 1 / 2$ was applied the Spearman Brown Prophecy Formula i.e. $r$ full $=\frac{2 r \frac{1}{2}}{1+r \frac{1}{2}}$ for computing the reliability of the full test, which was found to be $\mathbf{. 8 8}$

\section{VALIDITY}

Consequential to the unavailability of a nearly similar AEP attitude scale, the researcher had to depend only on content validity to establish the validity of the AEP attitude scale. For this, the scale was shown to AEP Master Trainers seeking their judgment regarding the coverage of contents and it was found satisfactory.

\section{ConClusion}

In the present paper attempt was made to construct and standardize an AEP attitude scale to measure the attitude of secondary school teachers towards the AEP intervention programme. The reliability of the scale being .88 and hence satisfactory, the scale is ready for administration on the targeted sample.

\section{REFERENCES}

[1] Arora, Pankaj. (2010). Sex Education in Schools. New Delhi: Ocean Books (P) Ltd.

[2] Best, John W. and James V. Khan. (2008). Research in Education. New Delhi: Prentice Hall Pvt. Ltd.

[3] Cohen, L., L. Manion, and K, Morrison. (2010). Research Methods in Education. Oxon: Routledge.

[4] De Souza, Susana, Barras and Marcos F. Elia. (1998). PHYSICS TEACHER'S ATTITUDES: HOW DO THEY AFFECT THE REALITY OF THE CLASSROOM AND MODELS FOR CHANGE? Retrieved on 01/04/2014 from http://pluslucis.univie.ac.at/Archiv/ICPE/D2.html

[5] Doctor NDTV. (2008). Adolescence the Wonder Years. Delhi: Byword Books Pvt. Ltd.

[6] Doctor NDTV. (2010). HIV and AIDS. Delhi: Byword Books Pvt. Ltd.

[7] Edwards, A. L. (1957). Techniques of Attitude Construction. Bombay: Vakils, Feffer and Simons Pvt. Ltd.

[8] Garret, Henry E. (1981). Statistics in Psychology and Education. Bombay: Vakils and Sons Ltd.

[9] Kaur and Kaur. (2012). Attitude of Parents and Teachers Towards Sex Education of Adolescents. Edusearh:Journal of Educational Research., Vol. 3 No. 1, 16-19.

[10] Koul, Lokesh. (2006). Methodology of Educational Research. New Delhi: Vikash Publishing house.

[11] NACO. (2008). Adolescence education Programme: Life Skills Development. Retrieved from http://www.naco.gov.in/upload/NACOinActiion/AEP\%20-\%20Teachers\%20Workbook.pdf

[12] NCERT. Adolescence Education Programme (four manuals).

[13] NCERT. (2005). National Curriculum Framework. 
[14] Neog, Madhuryya Madhab. (2005). A Study on the Attitude of Secondary School Level Teachers of Dergaon Town in Golaghat District of Assam towards Adolescence Education. Unpublished master's dissertation, Gauhati University, Gauhati, Assam.

[15] Nqoloba, Tembela. (2008). Attitude of Teachers Towards Sexuality and HIV and AIDS Education. University of Zululand. Retrieved from http://uzspace.uzulu.ac.za/bitstream/handle/ 10530/975/Attitudes\%20of\%20teachers.\%20T.\%20Nqoloba.pdf?sequence=1

[16] Rout, Gyanendra Kumar. (2012). Adolescence Education. New Delhi: A P H Pub. Corp.

[17] Sing, A K. (2006). Tests, Measurements and Research Methods in Behavioural Sciences. Patna: B B Printers. 